\title{
EL EROTISMO DE DON QUIJOTE
}

"... hubo un hombre que se pasó la vida
eludiendo a la mujer concreta... una mu-
jer de carne y hueso puso sitio al anaco.
reta [y éste] lejos de atrapar a la que te.
nía enfrente se echó en pos... de un
pomposo engendro de fantasía".
Jún José Arreola, Teoria de Dulcinea

Este epígrafe esboza la problemática afectiva de Alonso Quijano. El texto del Quijote permite una profundización del tema que puede centrarse, principalmente, en tres aspectos: las características del personaje como tímido erótico; su relación con las mujeres; y su itinerario psíquico, perceptible a lo largo de las dos partes de la novela.

\section{Alonso el tímido}

El texto cervantino presenta a un hombre de edad más que madura obsesionado por un objeto amoroso ideal ${ }^{1}$. Esto, que resalta de inmediato, suele impedir que el lector perciba estratos más profundos, ya no condicionados por la intención paródica, sino pertenecientes al auténtico dinamismo afectivo de la criatura novelesca. Lo amoroso genuino de esa criatura aparece, mucho más que en sus palabras - convencionales e imitativas invocaciones a Dulcinea y evocaciones de ella- en su actuación. Esa actuación revela que hay en él un erotismo normal aunque reprimido, por causas y mecanismos psíquicos muy complejos -como siempre ocurre en tales casos- y muy anteriores a la iniciación de la novela. El hecho es que Alonso Quijano tiene una fuerte y natural inclinación amorosa. Bien sabe defender $-y$ habla un poco por cuenta propia- al enamoradizo caballero Galaor. Dice: “... yo sé que en ese caballero... aquello de querer bien a todas cuantas bien le parecían, era condición natural, a quien no podía ir a la mano" (I-I3).

1 Está conjuntamente obsesionado por la acción heroica y caballeresca, pero hago deliberada abstracción del único aspecto que aquí he de sintetizar. 
En el hidalgo Quijano, la represión amorosa se explaya en la invención de una amada prácticamente inexistente -Dulcinea-, a pesar de su punto de apoyo en una mujer real y realmente amada en un tiempo que dura aún -Aldonza. Tal invención le permite, además, ignorar su inhibición, que se disfraza con la noble apariencia de fidelidad a la única y perfecta bienamada. Los alardes de esa fidelidad a Dulcinea aparecen cada vez que "lo eterno femenino" inquieta a Don Quijote. Aparecen como una especie de autoexhibicionismo de virtud amorosa. Representan, en realidad, esa racionalización enfermiza que consiste en apuntalar, con motivos aparentemente válidos, los movimientos psíquicos anómalos y la conducta por ellos provocada. Dulcinea -mujer ideal y abstracta- es el valladar que Alonso Quijano se ha levantado para evadir toda aproximación a la mujer real y concreta. La entrega total a Dulcinea es el puntal consciente de su miedo, más aún, de su terror subconsciente a la relación erótica.

Ese temor está explícito en varías partes del Quijote. Dice el héroe "... no es posible que yo arrostre, ni por pienso, el casarme" (I-30). En otro sitio: “. . . no soy casado, ni hasta ahora me ha venido el pensamiento de serlo..." (II-22). Y a propósito de las bodas de Camacho y Quiteria se refiere al matrimonio como a "un lazo que si una vez le echáis al cuello, se vuelve en el núdo gordiano..." (II-I9).

Pero la medrosa abstención está más patente en las actitudes del héroe. Primero, ante la Aldonza plenamente real: “... osaré jurar con verdad que en doce años que ha que la quiero... no la he visto cuatro veces; y aun podrá ser que de esas cuatro veces no hubiese ella echado de ver la una que la miraba..." (I-25). Después, respecto a Aldonza-Dulcinea: Don Quijote queda en la Sierra Morena y envía a Sancho al Toboso (el sitio real donde vive la mujer real, Aldonza) con una carta para Dulcinea. Es una manera de atreverse sin atreverse. $\mathrm{Y}$ ya en la segunda parte del libro, con la sensación de seguridad adquirida en un mes de reposo y reflexión, y con el precipitado impulso inicial característico del tímido, se lanza a buscar a Dulcinea en el pueblo de Aldonza. Pero a la vista del Toboso, el solterón vuelve a temer y se esconde; primero, tras la oscuridad de la noche; y llegado el día, tras la persona de Sancho y entre una frondosa arboleda (II-I0). Pero el climax del temor patológico al desengaño amoroso se da cuando Sancho enfrenta al hidalgo, no precisamente con la realidad de Aldonza, pero sí con una realidad que, muy plausiblemente, podría ser la de ésta. Ante la campesina que el escudero hace pasar por la qme busca Don Quijote, éste queda mudo, "con ojos desencajados y vista turbada"; se declara "el más desdichado de los hombres" y huye psicológicamente de am- 
bas mujeres: la real y la ideal (II-I0 ss.). Aquí se inicia el paulatino despego de Don Quijote hacia Dulcinea; despego que constituye una de las muchas diferencias entre el primer Quijote y el segundo ${ }^{2}$.

Otra característica del tímido erótico es la exigencia de perfección en el objeto amoroso. Con tal exigencia se protege de un enamoramiento que sólo es debido a lo perfecto-inexistente; pero si aún lo asaltare el temor de apegarse a lo que simultáneamente desea y esquiva, su exigente perfeccionismo es una garantía de que no llegará a ese apego sin las máximas cautela y seguridad. Largo y ocioso sería citar los innumerables pasajes en que Don Quijote puntualiza las perfecciones físicas de su dama ideal. Por otra parte, tales pasajes tienen mucho más de inerte parodia que de operante "realidad" novelística. En cambio, creo útil hacer notar su obsesiva preocupación por la virtud de la mujer-símbolo. Se advierte su paradójica inquietud al decirse seguro de la virtud de Aldonza, dado "el recato y encerramiento con que su padre... y su madre... la han criado" (I-25). De Dulcinea dice que es "grave sin soberbia, amorosa con honestidad, agradecida por cortés, cortés por bien criada y, finalmente, alta por linaje..." (II-32). Y ante la inquisición de terceros sobre este linaje, afirma y reafirma que su elegida "es hija de sus obras" y que su virtud "la puede llevar a ser reina" (ibid).

No podía faltar a Alonso Quijano esa otra característica del solterón, desde cierto ángulo simpática: la de ostentar su amor a la libertad propia de su estado. Traeré a cuento un ejemplo. Para mí está claro que Don Quijote no fue indiferente al "enamoramiento" de Altisidora, cosa que ejemplificaré más adelante. Sin embargo, instantes después de haber eludido esa ocasión amorosa, proclama el más satisfecho amor a la libertad: "Cuando Don Quijote se vio en la campaña rasa, libre y desembarazado de los requiebros de Altisidora... volviéndose a Sancho le dijo: La libertad, Sancho, es uno de los más preciosos dones que a los hombres dieron los cielos..." (II-58).

A pesar de esta ufanía, en varios pasajes se advierte en el hidalgo cierta nostalgia de la vida de familia y aun algo que no sé sí llamar envidia larvada hacia quienes la disfrutan. Me limitaré a un caso clave en el que Don Quijote actúa en forma desusada, y como inspirada por una rivalidad que nada tiene de caballeresca. Los capítulos I6, I7 y I8 de la segunda parte refieren la relación entre Alonso Quijano y Diego de Miranda. Éste era justamente lo que

2 Desde el punto de vista de la elaboración de la novela, esto -como otras muchas diferencias entre las dos partes- depende de la evolución cervantina v de la de sus personajes. Uno y otros dejan de estar atados a los convencionalismos de la parodia, para moverse con soltura creciente en el mundo de lo novelistico. 
aquél hubiera podido ser, de no mediar su trastorno psíquico: un terrateniente acomodado que ha formado una familia y goza con ella de afecto y de tranquila bienandanza. El gran parlamento final de Don Quijote, en el capítulo 17, es solapadamente comparativo: "Todos los caballeros tienen sus particulares ejercicios...; sirva a las damas el cortesano...; sustente a los caballeros pobres con el espléndido plato de su mesa...; muéstrese grande, liberal y magnífico y buen cristiano... ${ }^{3}$ Yo, pues como me cupo en suerte ser uno del número de la andante caballería, no puedo dejar de acometer todo aquello que a mí me pareciere que cae debajo de la jurisdicción de mis ejercicios..." Advierto esa comparación desenvolviéndose en la mente de Don Quijote durante la totalidad del episodio. La aventura de los leones - que desaforadamente rompe el intervalo amable que representa la relación entre Alonso Quijano y Diego de Miranda- me parece una reacción desesperada y exhibicionista. Alonso quiere vencer el sentimiento de carencia e inferioridad y se enfrenta - por única vez en toda la novela- a un grave peligro plenamente real. Quiere ostentar la superioridad de Don Quijote, caballero andante, sobre Don Diego, hidalgo sedentario, pacífico y "burgués". De ahí las despectivas palabras que dirige a éste, exabrupto en medio de una de las más apacibles y gratas relaciones que establece en su vida: "Váyase vuesa merced, señor hidalgo..., a entender con su perdigón manso y con su hurón atrevido, y deje a cada uno hacer su oficio. Este es el mío, y yo sé si vienen a mí o no, estos señores leones".

Una pincelada más en el retrato anímico del solterón manchego: su insatisfacción erótica se manifiesta en un casi delirio de persecución amorosa. Esta supuesta persecución le satisface en forma sustitutiva. Suele hacer alarde de ella y, muchas veces, del "desdén" y "enojo" con que a ella responde. En ciertos momentos, Alonso Quijano el Bueno llega a tener asomos de dureza (en el caso de Altisidora apuntaría al sadismo) para con las mujeres que "lo solicitan". En el segundo Quijote esto es más notorio, dadas las circunstancias: "Qué tengo de ser tan desdichado andante, que no ha de haber doncella que me mire que de mí no se enamore!... QQué tenga de ser tan corta la ventura de la sin par Dulcinea del Toboso, que no la han de dejar a solas gozar de la incomparable firmeza mía!... ¿Qué la queréis, reinas? ¿A qué la acosáis, doncellas de catorce a quince años? Mirad, caterva enamorada, que para sola Dulcinea

3 Poco antes, Don Diego ha dicho de sí mismo: “... paso la vida con mi mujer y con mis hijos... como con mis vecinos y amigos y muchas veces los convido; son mis convites limpios y aseados, y no nada escasos... reparto de mis bienes con los pobres... soy devoto de Nuestra Señora y confío siempre en la misericordia infinita de Nuestro Señor" (II-I6). 
soy..." (II-44). Y en otro lugar: "¿Qué te parece, Sancho...? ...Por tus mismos ojos has visto muerta a Altisidora... con la consideración del rigor y del desdén con que yo siempre la he tratado" (II-70) .

Esta actitud obsesiva de Alonso Quijano se hace notoria a quienes lo rodean. El primero en advertirlo es Sancho, pero quien expresa clara, aunque irónicamente, lo que ha observado es la $\mathrm{Du}$ quesa: “... señor Don Quijote..., andad con Dios, que mientras más os detenéis, más aumentáis el fuego en los pechos de las doncellas que os miran..." (II-57).

\section{Las mujeres de Alonso}

Don Quijote posee -ya lo he dicho- una fuerte y natural inclinación amorosa. La represión la transforma en un erotismo hiperestésico que funciona de dos maneras principales: sublimando al objeto erótico hasta espiritualizarlo por completo; o dejándolo como tal objeto erótico: deseable pero inaccesible, situado detrás de barreras psíquicas creadas por la mente misma del caballero.

Objetos eróticos sublimados son Dulcinea y todas aquellas mujeres a las que busca o imagina como necesitadas de su protección y a cuya admiración o gratitud -no a su amor- aspira. Éstas aparecen en el primer Quijote. Objetos eróticos no sublimados son Aldonza (a la que la afectividad de Don Quijote vuelve y vuelve a pesar de Dulcinea) y otras mujeres reales a las que se aproxima, ya no para socorrerlas, en el segundo Quijote ${ }^{4}$.

No es necesario insistir en la sublimación en el caso de Dulcinea; sí es conveniente observar que ella es la idealización de una mujer única $e$ inconfundible, objeto de un enamoramiento que, no por tímido e incompleto, es menos verdadero. Alonso Quijano jamás confunde a Dulcinea-Aldonza con ninguna de las bellas que encuentra en su camino, ni siquiera con la pastora Marcela o con alguna de las fingidas zagalas de la égloga, mujeres que, por su condición o apariencia campesina y por el marco agreste en que las halla, pudieran asociarse, en su espíritu, a la "moza labradora de muy buen parecer", lejana e idealizada, pero viviente en el Toboso.

A lo largo de sus primeras andanzas, Alonso Quijano tiene ocasión de sublimar a otras mujeres: a las "semidoncellas" Tolosa y Molinera transforma en damas cuya admiración intenta despertar.

4 Hay dos salvedades a la afirmación anterior: la hija del ventero, esa mujer concreta, la más próxima a Don Quijote desde el punto de vista erótico, aparece en la primera parte de la novela. Doña Rodríguez, que corresponde a la segunda, pertenece a las dos categorías: mujer real que sobresalta el "recato" del caballero, y viuda en desgracia cuya desventura toca a Don Quijote remediar. 
Se despide de ellas prometiendo "alguna parte de la honra que alcanzase por el valor de su brazo" y "ofreciéndoles nuevos servicios y mercedes" (I-3). De la señora vizcaína que viaja a Sevilla hace "una princesa" que va "hurtada" y declara: ". . . es menester deshacer este entuerto a todo mi poderío". Después de "salvarla" se presura a presentarse: “. . . por que no penéis por saber el nombre de vuestro libertador, sabed que yo me llamo Don Quijote de la Mancha" (I-8). "Puesta la mano en el puño de su espada, en altas e inteligibles voces" defiende a la pastora Marcela de sus acusadores, y después va tras ella; empeño en el que no cesa hasta haber "andado más de dos horas [por el bosque], buscándola por todas partes sin poder hallarla" (I-I4 y I5). En la aventura de los dos ejércitos, su intervención se debe nuevamente a una mujer, esta vez totalmente imaginaria, que necesita su auxilio: "la hija de Pentapolín, que es una muy hermosa y además agraciada señora, y es cristiana, y su padre no se la quiere entregar al rey pagano..." (I-I8). A DoroteaMicomicona ofrece: “. . . con la ayuda de Dios y la de mi brazo, vos os seréis presto restituida en vuestro reino..." (I-29). Durante su última permanencia en la venta-castillo, Don Quijote halla su empleo más satisfactorio en proteger a las mujeres: “... se ofreció a hacer la guardia del castillo, porque de algún gigante y otro malandante follón no fuesen acometidos, codicioso del gran tesoro de hermosura [Dorotea, Luscinda, Zoraida, Clara y la hija del "castellano"] que en aquel castillo se encerraba" (I-42). Y ante la procesión que lleva una imagen de la Dolorosa, se lanza a socorrer y liberar a tan "hermosa señora, cuyas lágrimas y triste semblante dan claras muestras [dice] de que la lleváis contra su voluntad..." (I-52).

Pero también hay mujeres a las que Alonso Quijano ve como tales, sin idealización alguna. En primer lugar está la misma Aldonza. A partir de ella ha creado a Dulcinea, pero no la ha aniquilado como objeto amoroso real y no sublimado. Dos veces - una indirecta y otra directamente- la busca en el Toboso, el pueblo en que realmente vive; y en sus escasos desahogos acerca de ella se advierte que su amor dista de ser platónico. Dentro de una convencional descripción de su belleza, se trasluce un dejo de erotismo que pertenece ya al mismo Alonso Quijano y no a la intención paródica de Cervantes: “. . . las partes que a la vista encubrió la honestidad son tales... que sólo la discreta consideración puede encarecerlas, y no compararlas" (I-I3). Y de otros pasajes puede deducirse que el solterón deseaba unirse sexualmente a Aldonza y tener hijos de ella. Por ejemplo, cuando la voz disfrazada del barbero le hace una falsa profecía. Tras oírla y creerla, Alonso Quijano quedó "consolado con la escuchada profecía; porque luego coligió... la significación de ella, y vio que le prometían el verse ayuntado... con su 
querida Dulcinea del Toboso, de cuyo feliz vientre saldrían... sus hijos..." (I-46).

En la segunda parte de su historia, Alonso Quijano ve en las mujeres que encuentra auténticas mujeres, por las que experimenta la normal atracción. En las palabras que les dirige ya no hay el convencional, arcaico y paródico "fermosa señora", y si llega a haberlo, por encima de él sustenta el caballero una actitud de contenido galanteo que lo lleva a compararlas con la sin par Dulcinea, cosa que en el primer Quijote hubiera sido imposible. En su desconcertante escisión afectiva, necesita la proximidad femenina y se acoge a ella para compensar su incapacidad de amar espontáneamente.

A este respecto, el encuentro con la Duquesa es significativo. Cervantes la presenta sólo como una hermosa cazadora vestida de verde, pero luego hemos de conocer su retrato. El texto habla de "aquella tez de rostro, que no parece sino una espada acilada y tersa, aquellas dos mejillas de leche y carmín... y aquella gallardía con que va pisando y aun despreciando el suelo..." (II-48). Inmediatamente antes de encontrarla, Alonso Quijano está "sepultado en los pensamientos de sus amores". En viéndola, experimenta por ella una atracción que no disimula: "Corre, hijo Sancho, y di a aquella señora... que yo... beso las manos de su gran hermosura, y que si su grandeza me da licencia, se las iré a besar y a servirla...; y mira, Sancho, cómo hablas... ; ve en buena hora y Dios te guíe" (II-30). Una página después la llama "digna señora de la hermosura y universal princesa de la cortesía", en tono tal que el Duque tiene que reconvenirle: ". . a donde está mi señora Dulcinea del Toboso, no es razón que se alaben otras hermosuras"; palabras a las que Alonso Quijano hace oídos sordos, de modo que Sancho tiene que contestarlas. Más adelante, Don Quijote hará esta relación entre ambas mujeres: "Más venturosa y más conocida será en el mundo Dulcinea por haberla alabado vuestra grandeza [habla a la Duquesa] cme por todas las alabanzas que puedan darle los más elocuentes de la tierra" (II-44). Mientras el solterón se halla en la proximidad de esta mujer, no sólo omite sus ponderaciones de la excelencia de Dulcinea, sino que elude hablar de ella o, forzado a hacerlo, parece querer degradar su recuerdo o reconocer como dudosa su existencia: "Señora mía [dice a la Duquesa], Dulcinea está encantada y vuelta en la más fea labradora que hablar se puede" (ÎI-31). Y más adelante: “... Dios sabe si hay Dulcinea o no en el mundo; o si es fantástica o no es fantástica; y estas no son cosas cuya averiguación se ha de llevar hasta el cabo" (II-32).

$\mathrm{Su}$ actitud ante otras mujeres que aparecen en la segunda parte es también reveladora. El fingido amor de Altisidora lo lleva a una verdadera crisis, cuya reminiscencia dura en su ánimo hasta las pá- 
ginas finales del libro. Hay que notar su temor a la proximidad de la atrevida doncella, su confesión de que los deseos de ésta "engendraron en [su] pecho confusión" (II-58) ; su empeño por demostrar a Sancho, y quizá a sí mismo, que verdaderamente él, Alonso, pudo haber encendido el violento amor de la jovencita: "Yo, Sancho, bien veo que no soy hermoso; pero también conozco que no soy disforme; y bástale a un hombre de bien no ser monstruo para ser bien querido, como tenga las dotes del alma..." (ibid.). En otro lugar y ante Roque Guinart, sus palabras revelan el apego sentimental que tiene a las prendas personales de Altisidora que ésta le puso, mañosamente, entre el equipaje (II-60); y de regreso de Barcelona, después de la conversación de Tosilos con Sancho, pregunta ansiosamente a su escudero: "Dime ahora...., ¿preguntaste a ese Tosilos... qué ha hecho Dios de Altisidora: si ha llorado mi ausencia, o si ha dejado ya en las manos del olvido los enamorados pensamientos...?" Poco después parece dolerse del bloqueo erótico que se disfraza de fidelidad a Dulcinea: "Yo no tuve esperanza qué darle ni tesoros qué ofrecerle, porque los más [ya no todos, como hubiera dicho en el primer Quijote] tengo entregados a Dulcinea..." (II-67) .

Es también notable su actitud ante otras mujeres. Las doncellas "hermosas como unas flores" que la Duquesa destina a su servicio no son ya damas ideales sino mujeres de carne y hueso que despiertan, simultáneamente, su deseo y su temor, hasta hacerle poner, tajantemente -él mismo lo expresa-, "una muralla en medio de mis deseos y de mi honestidad" (II-44). Doña Rodríguez, con toda su dueñez a cuestas, levanta en él una tempestad similar: "¿Quién sabe [se pregunta el tímido] si esta soledad, esta ocasión y este silencio despertará mis deseos?" $\mathrm{Y}$ aunque intenta tranquilizarse ("¿Por ventura hay dueña en la tierra que tenga buenas carnes?"), termina diciendo a la mujer: "... ni soy de mármol, ni vos de bronce, ni ahora son las diez del día, sino medianoche... y en una estancia... cerrada y... secreta..." (II-48).

Salidos amo y mozo del palacio ducal, el primero tiene nueva ocasión de galantear. A las dos rubias y fingidas pastoras, cuyo convite acepta, pondera: " $i \ldots$ he quedado atónito en ver vuestra belleza!" Cuando ellas -que saben ya de Dulcinea- declaran que "en toda España le dan la palma de la hermosura", el hidalgo corrige: “... si ya no lo pone en duda vuestra sin igual belleza". Afirma que las falsas pastoras "son las más hermosas doncellas... que hay en el mundo" y se ofrece a sostener tal verdad con las armas en la mano. En todos estos galantes afanes, apenas si dos veces se acuerda de añadir a los superlativos que aplica a la belleza de las zagalas - como un estribillo impuesto y gastado por la costumbre- "excep. tuando sólo a la sin par Dulcinea del Toboso" (II-58). 
Ya hacia el final de su historia, cuando ha ido descendiendo por los peldaños de la astenia y no parece moverse más que por la inercia del impulso recibido de otros, aún le inquieta la mujer. En el sarao barcelonés de Don Antonio Moreno, ante las insinuaciones de dos mujeres "de gusto picaro", tiene que acudir a la violencia, recurso del débil, para defenderse de sí mismo más que de ellas: "... alzó la voz y dijo: $i$... Dejadme en mi sosiego, pensamientos mal venidos. Allá os avenid, señoras, con vuestros deseos; que la que es reina de los míos... no consiente que ningunos otros que los suyos me avasallen y rindan!" (II-62).

Trato al final el caso de la hija del ventero, por ser único y climático. Alonso Quijano, herido, llega a la venta-castillo que tanto significa en su historia. Cervantes cuenta que la mujer del ventero "hizo que una hija suya, muchacha y de muy buen parecer, la ayudase a curar a su huésped". Ésta y la criada del mesón -la famosa Maritornes- "hicieron una... cama a Don Quijote en su camaranchón", o sea, en el desván de la venta (I-I6). La anécdota es bien conocida: el iluso hidalgo imagina que la hija del ventero es una noble doncella, hija del señor del castillo, y se cree amado por ella. Cuando Maritornes entra al oscuro desván para meterse en la cama de un arriero que ahí mismo se aposenta y que le ha dado cita, tropieza con el lecho de Don Quijote. Éste, que se ha sentido vivamente impresionado por la jovencita, cree ome es ella la que llega a su cama para tomar la iniciativa amorosa. Y se rompen, por breve lapso, las barreras psíquicas de su represión. Dice el texto: “... la sintió y, sentándose en la cama..., tendió los brazos para recibir a su hermosa doncella..., la asió fuertemente de una muñeca y tirándola hacia sí... la hizo sentarse sobre la cama. Tentóle luego la camisa... y teniéndola bien asida, con voz morosa y baja le comenzó a decir: -Quisiera hallarme en términos, hermosa y alta señora, de poder pagar tamaña merced... La moza forcejeaba por desasirse y Don Qnijote trabajaba por tenerla..." (I-17). Desde luego, en este parlamento sale muy luego a relucir la fidelidad a Dulcinea que impide al caballero el cumplimiento de su obvio deseo sexual; pero nunca como aquí se ve tan cerca de lograr la ruptara de sus inhibiciones. Nos preguntamos qué hubiera ocurrido si Don Quijote no hubiera estado herido y maltrecho y si el puñetazo del arriero y el consiginente alboroto no hubieran interrumpido el tête-à-tête en que la oscuridad permitió a Maritornes ser confundida con Ia encantadora "hija del castellano". Rasgos sutiles y sugerentes ofrece el texto cervantino respecto a la relación entre esta mujer casi niña y el cincuentón Quijano. Quien los rastrea con atención, no puede negar que ésta es la figura femenina más auténtica y sobresaliente del Quijote; que, novelísticamente, es obvio que la venterita es la única 
mujer que el solterón se permite desear; y que ella, a su vez, es la única que pone en él un interés próximo al interés amoroso. Queda perfectamente claro que aquí Don Quijote "aprincesa” a una mujer sin deshumanizarla ni sublimarla ${ }^{5}$.

\section{De Aldonza a Dulcinea... Y viceversa}

Seguir paso a paso la trayectoria anímica de Don Quijote sería largo y minucioso. Simplifico, pues, y tomo únicamente sus momentos culminantes y decisivos.

El principio de la novela muestra el climax del trastorno mental del protagonista, que aparece como el desdoblamiento de Alonso Quijano en Don Quijote de la Mancha. Ese climax presupone un itinerario psíquico que no fue la intención de Cervantes mostrar pero que es, en su línea fundamental, evidente. Cuando el autor

5 De paso, me parece interesante mirar la otra cara de la moneda, es decir, lo que Cervantes apunta de la corriente anímica que va de la muchacha hacia el hidalgo. El interés de ésta se muestra de inmediato: "¿Qué es caballero aventurern?" (I-I6), pregunta. Y en su interrogante hay algo más que mera curiosidad, como Cervantes señala al singularizar a este personaje entre todos: "Estábanle mirando [a Don Quijote] todos cuantos había en la venta; mirábale también la hija del ventero" (I-I7). Más adelante volverá a destacarla empleando el procedimiento que, dentro de su estilo, está reservado para revelar las intimidades de Don Quijote y de Sancho: el diálogo. Cuando, ausentes ambos, en la venta se discute sobre la quijotesca enfermedad de amor: “-Y a vos ¿qué os parece, señora doncella? -dijo el Cura hablando con la hija del ventero-. No sé lo que me hiciera -respondió ella-, ...las lamentaciones que los caballeros hacen cuando están ausentes de sus señoras... en verdad que algunas veces me hacen llorar, de compasión que les tengo. -Luego ¿̨bien las remediarais vos, señora doncella... si por vos lloraran? -No sé que me hiciera -respondió la moza-; sólo sé que hay algunas señoras de aquellas tan crueles... yo no sé que gente es aquélla, tan desalmada y tan sin conciencia, que por no mirar a un hombre honrado [no dice: a un "caballero"] le dejan que se muera o que se vuelva loco" (I-32). Durante los turbulentos sucesos en que Don Quijote es objeto general de cóleras o de burlas, "la hija callaba, y de cuando en cuando se sonreia" (I-35). Más adelante, cuando el caballero hace la guardia de la venta-castillo, la hija y Maritornes "determinaron las dos de hacerle alguna burla o, a lo menos, de pasar un poco el tiempo oyéndole..." El caso es que la hija se limita a escuchar en silencio el larguísimo desahogo de Don Quijote sobre sus desdichas amorosas, y que la cruel burla que se sigue corresponde a Maritornes en la invención y la ejecución (I-43). Cuando el ventero tiene urgente necesidad de auxilio, sólo la hija, espontánea y confiadamente, lo nide a Don Quijote: "Socorra vuestra merced, señor caballero, por la virtud que Dios le dio, a mi nobre padre..." (I-44). Finalmente, cuando el héroe sale de la venta para no volver a ella, las tres mnjeres de la misma (una de ellas la hija) salen "a despedirse de Don Quijote, fingiendo que lloraban de dolor de su desgracia" (I-47). Tal vez ésta, la única figura de majer tratada en forma realmente novelística, aunque incompleta, hubiera podido llegar a ser el protagonista femenino del Quijote. 
nos dice que al hidalgo "... del mucho leer se le secó el cerebro, de manera, que vino a perder el juicio" (I-I), no está expresando la causa del desequilibrio, sino un síntoma del mismo, ya avanzado. Ese nocturno y desaforado leer para vivir en el mundo artificial de lo leído es indicio de una alienación, de una anormalidad afectivoemotiva largamente incubada. Al llegar a ese clímax, el personaje, simultáneamente, expulsa o trata de expulsar de su conciencia al objeto real que lo perturba: Aldonza Lorenzo, y lo sustituye por otro eróticamente inocuo: Dulcinea del Toboso. Pasada la primera serie de sus "aventuras" -vividas todas en función de Dulcineallega a la Sierra Morena y decide penar allí por su dama, como Amadís por la suya en el retiro de la Peña Pobre. Hasta aquí, ha ido de Aldonza a Dulcinea. Pero la soledad sin aventuras es monótona y obliga a pensar. Esto, junto con el encuentro y la plática de Cardenio - "loco" de amor en esa misma soledad-, suscita en el caballero un importante cambio psíquico. No deja su monomaniaca evocación e imitación de los caballeros andantes, pero llega a expresar repetidamente, por única vez en toda la obra, la identidad de la labradora con Dulcinea. Es más, envía a su amada una carta real, con un mensajero real, al lugar en que realmente vive. Podría decirse que Aldonza ha vuelto a ser aceptada en la psique consciente de Alonso. Así, éste da el primer paso en su intermitente evolución de lo irreal a lo real, de Dulcinea a Aldonza. Hago abstracción de los complejos y largos sucesos de la venta y del "encantamiento" de Don Quijote que lo devuelve, por un mes, a su lugar y casa; y lo hago porque en todo esto el héroe, asténico, es manipulado por otros. En ese mes de reposo cobra energía y se autodetermina, directa y precisamente, a buscar a Aldonza -aunque la siga llamando Dulcinea- en el Toboso. Ya he dicho cómo vuelve a temer y a ocultarse; ahora añado que la triquiñuela de Sancho le da la oportunidad de disfrazar este nuevo brote de su enfermizo temor. Sentir que Dulcinea está encantada es una manera de sentir que Aldonza es maccesible, "porque [en palabras del propio Don Quijote] el que está encantado. . . no tiene Iibertad para hacer de su persona lo que quisiere..." (I-49). Una vez "encantada", AldonzaDulcinea carece de la facultad de responder o corresponder a Alonso-Don Quijote. Por lo tanto, es inútil que éste la requiera en una o en otra forma. Tal certeza absuelve y refuerza la represión erótica del personaje, aunque de manera cada vez más precaria.

Efectivamente, toda la segunda parte de la novela es la historia de la obsesión de Don Quijote por el "desencantamiento" de Dulcinea, es decir, de la obsesión de Alonso por la ruptura del bloqueo que lo separa de la mujer concreta. No creo que tal interpretación sea demasiado aventurada; el texto le ofrece un fuerte apoyo. En 
el capítulo 58 de la segunda parte, el héroe pronuncia estas palabras: "... yo hasta ahora no sé lo que conquisto a fuerza de mis trabajos; pero si mi Dulcinea del Toboso saliese de los que padece, mejorándose mi ventura y adobándoseme el juicio, podría ser que encaminase mis pasos por mejor camino del que llevo". Aquí, por única vez antes de su cordura final y definitiva, Alonso Quijano reconoce su trastorno mental y habla de la posibilidad de verse libre de él. Es de notar que tal posibilidad de cordura está asociada con la del "desencantamiento", es decir, la accesibilidad psíquica de la mujer-símbolo. Más aún, el hidalgo habla de esa posibilidad de salud mental ("adobándoseme el juicio") y de dicha ("mejorándose mi ventura"), como una consecuencia de esa accesibilidad de lo femenino ${ }^{6}$. Esta declaración de Don Quijote ha llamado la atención de muchos comentaristas. Amado Alonso, por ejemplo, llega a sugerir que aquí se insinúa la idea de un Don Quijote curado de su monomanía, y aun casado.

El hecho es que Alonso Quijano, en las últimas páginas de su historia, ya no se oculta ni envía a Sancho como vanguardia de su amorosa ansiedad. En la postrera jornada de amo y criado "no toparon mujer ninguna que no iba [Don Quijote] a reconocer si era Dulcinea del Toboso" (II-72). Cierto es que sigue llamando Dulcinea a la mujer real que, ahora sí, desea encontrar; pero cierto es también que no la busca, pasajera en algún "carruaje" o resguardada en algún "castillo", sino caminante a pie por los senderos de la Mancha. Esta búsqueda resulta inútil y el solterón vuelve a su casa para morir negando a Dulcinea, y sin haber tenido tiempo para encontrar a Aldonza.

Dice Américo Castro: "La mujer es para Cervantes [se refiere al escritor, no al hombre] el más tremendo imperativo vital, contra el que suelen estrellarse los pocos avisados; lo femenino o da lugar a dulce y apacible armonía, o es término funesto y desastrado. Para Cervantes no son ellas únicamente seres blandos y suaves necesitados de la protección masculina. La mujer es un temible problema" ' Esta afirmación, aplicable a la totalidad de la obra cervantina, lo es muy especialmente al Quijote. Su protagonista es uno de estos "poco avisados" para quienes la mujer es "el más tremendo imperativo vital" y también, por desgracia, "término funesto y desastrado".

El Colegio de México.

Teresa Aveleyra-S.

- Aquí cabría alguna puntillosa discusión sobre el uso cervantino de los gerundios en este parlamento. Dudo que pudiera llegarse a conclusiones. En todo caso éstas no afectarían al amplio significado de tan singulares palabras.

7 El pensamiento de Cervantes, Madrid, 1925, pp. 383-384. 